\title{
Assuring nuclear safety education in the twenty-first century in Sweden
}

\section{G. Löwenhielm*}

Swedish Nuclear Power Inspectorate (SKI),

Stockholm, SE-10658, Sweden

E-mail: gustaf.lowenhielm@ski.se

\section{T. Lefvert}

Swedish Nuclear Technology Centre,

Department of Physics,

Royal Inst. of Technology, SCFAB

Stockholm, SE-106 91, Sweden

E-mail: tomas@physics.kth.se

${ }^{*}$ Corresponding author

\begin{abstract}
One of the most critical challenges in the future for nuclear technology is to maintain nuclear competence. In this paper, the work to cope with this challenge in Sweden is described. The main measure has been the cooperation between the authorities and the nuclear power industry in the Swedish Centre for Nuclear Technology. In the year 2002, its activity only to support $\mathrm{PhD}$ students was expanded to also include support to three universities and institutes of technology for professorships and other posts. The conclusion is that this support has secured future undergraduate and postgraduate programmes at an adequate level up to the year 2010 .
\end{abstract}

Keywords: nuclear safety education; nuclear safety competence; competence need.

Reference to this paper should be made as follows: Löwenhielm, G. and Lefvert, T. (2005) 'Assuring nuclear safety education in the twenty-first century in Sweden', Int. J. Nuclear Knowledge Management, Vol. 1, No. 4, pp.345-350.

Biographical notes: Gustaf Löwenhielm took his $\mathrm{PhD}$ degree in Reactor Physics in 1978. He started his professional career at the Swedish Nuclear Power Inspectorate, where he started at the Research Department and also worked in the Waste department. In 1980, he started to work at the Swedish utility Vattenfall as an expert in severe accidents and radiological safety. From 1986, he was the head of the severe accident group, which later also included radiological safety. In 1995, Gustaf Löwenhielm became the head of the Safety Group at Forsmark NPP. In 1999, he became the Research Director in the Swedish Nuclear Power Inspectorate. Gustaf Löwenhielm has participated in numerous international groups in the severe accident area and published about 15 scientific papers at international conferences and in journals. He also participates in international research groups, e.g. CSNI and EU CCE-Fission. 
Tomas Lefvert, who took his $\mathrm{PhD}$ in Reactor Physics in 1974 and was appointed Associate Professor in 1978, worked between 1966 and 1978 for the Swedish Defence Research Institute. From 1978, he has worked for the Swedish utility Vattenfall. At Vattenfall, he has been managing departments on code development, reactor physics, safety analysis and reactor fuel technology. $\mathrm{He}$ is now a corporate scientific advisor at Vattenfall, adjunct professor in reactor physics at the Royal Institute of Technology in Stockholm and Director of the Swedish Centre for Nuclear Technology.

\section{Introduction}

Maintaining nuclear competency in nuclear regulatory authorities and the nuclear industry will be one of the most critical challenges in the near future, which has been investigated several times in recent years (OECD/NEA, 2000a, 2000b, 2001). The challenge arises because in the Western world the industry has, with a few exceptions, no new order on line. The regulators and the industry thus have an ageing work force with knowledge of construction of reactors. Coupled with the stagnation of the industry, there has been a decline of students graduating from courses in nuclear science and engineering. As a consequence, universities hesitate to replace a retiring professor in nuclear-related subjects with a new professor in the same subject. Therefore, it is a high risk that education in nuclear-related subjects is negatively affected.

In this context, it is important to point out the responsibility of each state according to the Nuclear Safety Convention. In paper 11.2, it is stated:

"Each Contracting Party shall take appropriate steps to ensure that sufficient numbers of qualified staff with appropriate education, training and retraining are available for all safety-related activities in or for each nuclear installation, throughout its life."

In this paper, it is described how Sweden has taken this responsibility in the aspect of education at universities to fulfil its obligation to the Nuclear Safety Convention.

\section{Threats towards nuclear education}

During the year 2000, the threat against the education situation in Sweden was discussed. The reasons for this threat were:

- deregulation of the electricity market (leading to strong competition)

- decision to close Barsebäck 1

- at universities

- less funding from the state to universities

- nuclear subjects not a 'hot' subject to study

- retiring professors in nuclear research may not be replaced in the same area.

The Government's appropriations directive to SKI for 2001 (and every year since then) states that "SKI shall take action to ensure that the competence required for the safety and non-proliferation work is maintained and developed within SKI as well as at the licensees 
and elsewhere in the country". The report shall show how the nuclear safety research has been used for this purpose. In this aspect, the year 2001 was a very interesting year in Sweden since undergraduate and postgraduate education at universities wound up in the risk zone when several professors were going to be retired.

\section{Swedish centre for nuclear technology}

Early in the 1990s, it became clear that the financial situation at the universities and the institutes of technology led to problems in financing the PhDs on their own. SKI had discussions with the industry and it was agreed to set up the Swedish Centre for Nuclear Technology (SKC), which was started in 1992 and has been described in (Tirén, 1994). The financial parties were SKI, Westinghouse and the four NPPs. Up to the year 2001, the main activity of the Centre was to support PhD students (with scientific advice and economy) in topics related to nuclear technology. This activity has gradually expanded and today about 10-12 young engineers are supported in this programme at seven universities/institutes of technology. Altogether 7 doctoral dissertations and 11 licentiate dissertations have been published by SKC-supported engineers. Besides this support from SKC, SKI finances professorships in Nuclear Safety at the Royal Institute of Technology (KTH) and in the Man-Technology-Organisation (MTO) at the University of Stockholm.

As mentioned above, the undergraduate and postgraduate education at universities came into the risk zone in 2001 as four professors were going to retire in the near future. In this situation, the Royal Institute of Technology announced that financial support was needed to fill some of these positions. This applied to the professorships in Nuclear Chemistry and Reactor Technology at KTH. KTH also needed support for the professorship in Reactor Physics. Chalmers University of Technology (CTH), on the other hand, had decided to appoint a replacement for the professorship in Nuclear Chemistry.

Swedish Nuclear Fuel and Waste Management Co (SKB) decided to support the professorship in Nuclear Chemistry at $\mathrm{KTH}$, and the partners of SKC were willing to sponsor the professorships in Reactor Technology and Reactor Physics. Therefore, KTH decided to advertise the vacancies in Nuclear Chemistry and Reactor Technology. In the ensuing negotiations between the financial partners of SKC, it was decided to broaden SKC's mission to include direct support to the posts at KTH, CTH and UU (University of Uppsala). Furthermore, agreements have been drawn up between SKC's partners and the individual universities. All agreements are valid for six years. To cover the increased costs, SKC's budget was increased, starting in 2002, to SEK 16 million (about 1,7 million Euro) from a former level of about SEK 10 million (about 1,1 million Euro) per year. SKI's share is one-third of the costs. In the negotiations with the institutes of technology and universities, it was found necessary to support two posts at UU and two lectureships at $\mathrm{CTH}$ and $\mathrm{KTH}$, respectively. Besides this support from SKC, SKI continues its support to the professorship in Nuclear Safety at KTH and MTO at the University of Stockholm.

Other activities of the SKC include organising a national school for graduate students and a prize for the best Master and PhD Thesis. SKC is furthermore present at the universities' job fairs with an exhibition to attract students to nuclear-related courses. 


\section{Education situation in Sweden in nuclear-related subjects}

The most important universities for education in nuclear-related subjects are:

- Royal Institute of Technology (Stockholm)

- Chalmers University of Technology (Gothenburg)

- University of Uppsala (Uppsala).

A brief description of the education situation within these universities is given below. Here, the importance of research to keep the education attractive should be noted.

\subsection{Royal Institute of Technology}

The Royal Institute of Technology (KTH) has for a long time upheld education in nuclear engineering, reactor physics and nuclear chemistry. Up to 2002, there were four professors leading the Divisions of Nuclear Reactor Technology, Nuclear Safety, Reactor Physics and Nuclear Chemistry with substantial research in these areas.

The professor chair in Nuclear Safety has been supported by SKI since the beginning of the 1980s. Since about 1994, the main focus of the research has been on severe accidents and experimental resources, which must be regarded as a national asset, have been built up. The EU has financed much of this work through the framework programme. The Division of Nuclear Reactor Technology has experimental equipment for measurement of two-phase flow and critical safety parameters. New professors will in the near future fill these vacant professorships. Besides these professorships, a new lector has been employed, who has the task further developing the education material.

The research at the Reactor Physics department has mainly been devoted to the transmutation technique, which is an example of a new technique, which has attracted students.

\subsection{Chalmers University of Technology}

The Chalmers University of Technology (CTH) has for a long time upheld education and research in reactor physics and nuclear chemistry. There is one professor in reactor physics and three in nuclear chemistry. With the contract between SKC and CTH, this has been broadened with a lectureship in Nuclear Engineering and SKC expects this will mean that education in this subject will start fairly soon.

The activities at the Division of Reactor Physics are focused on maintaining and developing competence regarding the effects of e.g., core optimisation and core surveillance. In the Division of Nuclear Chemistry, the work is of great importance for the safety assessment of the final disposal of spent nuclear fuel. The number of professors in Nuclear Chemistry is unchanged and no extra support was deemed necessary when the contract between SKC and CTH was formed.

\subsection{Uppsala University}

The education at UU in nuclear-related subjects has been related to radiation and radiation measurement techniques. The research of importance has been related to nuclear waste and nuclear non-proliferation. SKC has, in the contract with UU, granted 
support so that UU can retain (which otherwise would not have been possible) a senior researcher and a postdoctoral fellow with a special focus on reactor and fuel technology.

\section{The strategic competence needs in Sweden}

When SKI's research strategy was developed, one part of the strategy was to also look at the competence in strategic competence areas, and to quantify the need today and in a ten-year perspective. The report can be found (in Swedish) in its entirety in Karnik and Hammar (2001). A summary of the report in English can be found in SKI (2002).

The study was conducted in the form of a survey, where a questionnaire was sent to the utilities and seven other organisations, including SKI. In the questionnaire, 11 competence areas were defined and for each area the respondent was asked to stipulate the availability of personnel in 2010, the turnover of personnel and the need for external contractors. Altogether, the data gathered covered 709 employees, with levels of education and experience in the industry as shown in Table 1. According to the report, the age distribution over all educational levels is such that it does not lend support to the fear that a very large proportion of competence will be lost in about ten years. The report does, however, point out that the oldest age category contains a high proportion of the individuals who actually designed the nuclear power plants.

The forecast for 2010 indicates some increase in the personnel need, on the order of $10 \%$, for university-educated personnel, while the need for postgraduate-level personnel is predicted to decrease slightly. Clearly increased personnel need is found within process monitoring and process control, as expressed by the nuclear power plants, but otherwise the changes are generally small.

Table 1 Distribution of employees according to experience and level of education in questionnaire responses SKI (2002)

\begin{tabular}{lcccc}
\hline & \multicolumn{4}{c}{ Experience, number of years } \\
\cline { 2 - 5 } Education & $<2$ years & $2-5$ years & $>5$ years & All \\
\hline Postgraduate & 7 & 12 & 76 & 95 \\
180 points $^{1}$ & 35 & 76 & 319 & 430 \\
120 points $^{2}$ & 20 & 39 & 125 & 184 \\
\hline Total & 62 & 127 & 520 & 709 \\
\hline
\end{tabular}

${ }^{1}$ University degree with 180 points (Master of Science).

${ }^{2}$ University degree with 120 points (Bachelor of Arts or Bachelor of Science).

The annual recruitment needed to maintain the competence level could be estimated from the data in the completed questionnaires within different competence areas and personnel turnover figures for the last five years. The total annual recruitment need is judged to be about 50 people in the organisations that participated in the survey. It is SKI's judgement that the present-day educational capacity of university institutions in Sweden is sufficient and that measures described in this paper will help to maintain the undergraduate education. 


\subsection{Effect of measures}

Of course, it is important to follow up what the effects of the increased support to the universities and institutions of technology are to the education and research. Actually, there is a hope for a leverage effect; i.e., it is possible that universities and institutions of technology can be seen as an attractive partner in international research such as EU projects. The agreements between SKC and KTH, and CTH and UU are valid for six years. This means that at the end of this year (2004) these agreements have been in effect halftime. SKC has decided to evaluate the effects of the cooperation so far. The feeling the authors have before this evaluation is that if the agreements had not come into place several professorships in nuclear subjects would have disappeared with a severe negative effect on education and research. The authors also have a feeling that the situation has improved and that more students have been attracted to nuclear-related subjects. There are other factors affecting the number of students attending nuclear courses and the trend today is that nuclear power has a more positive image, due to e.g., Finland's decision to build a new nuclear power plant and the Generation IV activities.

The authors find it highly gratifying that SKI and the nuclear power industry have secured future undergraduate and postgraduate programmes at $\mathrm{KTH}, \mathrm{CTH}$ and $\mathrm{UU}$. As mentioned above, the need is about 50 university-educated persons per year (Karnik and Hammar, 2001) The same study also shows that the present education level is sufficient to cover this need since the retirements within the next ten-year period will not increase as feared. Therefore, the measures adopted by SKC to maintain the present education level can be seen as adequate. However, the halftime evaluation that is now under way will probably give ideas on how to improve the efficiency of the cooperation between SKC and the universities.

With these agreements, SKI has, together with the power industry, clearly demonstrated its intention to ensure that competence is maintained and developed according to the commitment to the Nuclear Safety Convention in the education aspect. It is, however, important to follow up how well the institutes of technology and universities attract engineering students in nuclear power-related courses and also postgraduate students.

\section{References}

Karnik, P. and Hammar, L. (2001) 'Kartläggning av strategiska kompetensbehov för kärnteknisk verksamhet i nuläget och för framtiden (Mapping of strategic competence needs for nuclear activities at present and in the future, only in Swedish)', SKI Report, 01:36.

OECD/NEA (2000a) Nuclear Education and Training: A Cause for Concern?, Paris.

OECD/NEA (2000b) 'Assuring nuclear safety competence into the 21st century', Workshop Proceedings, Budapest, Hungary, 12-14 October, 1999.

OECD/NEA (2001) Assuring Future Nuclear Safety Competence - Specific Actions, Paris.

SKI (2002) 'SKI:s research strategy', SKI Report, 02:45, pp.55-59.

Tirén, L.I. (1994) 'Nuclear technology centre - preserving and developing competence and resources', Energy Technology, Royal Institute of Technology, Stockholm, Sweden, Proc. on the Nuclear Power, IAEA, September 5-8, Vienna. 